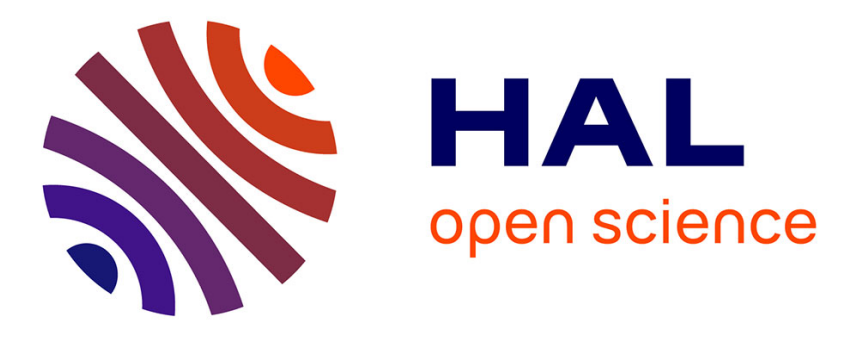

\title{
Steroid modulation of neurogenesis: Focus on radial glial cells in zebrafish
}

Elisabeth Pellegrini, Nicolas Diotel, C. Vaillant-Capitaine, R. Pérez Maria, M.-M. Gueguen, A. Nasri, J. Cano Nicolau, O. Kah

\section{- To cite this version:}

Elisabeth Pellegrini, Nicolas Diotel, C. Vaillant-Capitaine, R. Pérez Maria, M.-M. Gueguen, et al.. Steroid modulation of neurogenesis: Focus on radial glial cells in zebrafish. Journal of Steroid Biochemistry and Molecular Biology, 2016, 160, pp.27-36. 10.1016/j.jsbmb.2015.06.011 . hal-01174214

HAL Id: hal-01174214

https://hal-univ-rennes1.archives-ouvertes.fr/hal-01174214

Submitted on 19 Nov 2015

HAL is a multi-disciplinary open access archive for the deposit and dissemination of scientific research documents, whether they are published or not. The documents may come from teaching and research institutions in France or abroad, or from public or private research centers.
L'archive ouverte pluridisciplinaire HAL, est destinée au dépôt et à la diffusion de documents scientifiques de niveau recherche, publiés ou non, émanant des établissements d'enseignement et de recherche français ou étrangers, des laboratoires publics ou privés. 


\section{STEROID MODULATION OF NEUROGENESIS: \\ FOCUS ON RADIAL GLIAL CELLS IN ZEBRAFISH}

Pellegrini Elisabeth $^{\mathrm{a}^{*}}$, Diotel Nicolas ${ }^{\mathrm{a}, \mathrm{b}, \mathrm{c}}$, Vaillant-Capitaine Colette ${ }^{\mathrm{a}}$, Pérez Maria Rita ${ }^{\mathrm{a}, \mathrm{d}}$, Gueguen Marie-Madeleine $^{\mathrm{a}}$, Nasri Ahmed ${ }^{\mathrm{a}, \mathrm{e}}$, Cano Nicolau Joel ${ }^{\mathrm{a}}$, Kah Olivier ${ }^{\mathrm{a}}$

a) Inserm U1085, Université de Rennes 1, Research Institute in Health, Environment and Occupation, 35000, Rennes, France

b) Inserm UMR 1188, Diabète athérothrombose Thérapies Réunion Océan Indien (DéTROI), plateforme CYROI, Sainte-Clotilde, F-97490, France

c) Université de La Réunion, UMR 1188, Sainte-Clotilde, F-97490, France

d) Laboratorio de Ictiología, Instituto Nacional de Limnología (INALI. CONICET-UNL), Paraje El Pozo, Ciudad Universitaria UNL, 3000 Santa Fe, Argentina

e) Laboratoire de Biosurveillance de l'Environnement, Unité d'Ecologie côtière et d'Ecotoxicologie, Faculté des Sciences de Bizerte, Zarzouna 7021, Tunisie

*Address for correspondence:

Dr. Elisabeth Pellegrini

Research Institute in Health, Environment and Occupation

INSERM U1085, SFR Biosit

Université de Rennes 1

Campus de Beaulieu

35042 Rennes cedex

France

tel: +33223236749

fax: +33223236794

elisabeth.pellegrini@univ-rennes1.fr

Highlights

The brain of adult zebrafish is a source of steroids and target of steroids.

Aromatase expression is restricted to radial glial cells in the adult zebrafish.

Radial glial cells are progenitor cells in the brain of adult zebrafish.

Estradiol negatively regulates the proliferation and the migration of newborn cells.

Aromatase expression is induced in parenchymal cells after mechanical injury.

Abstract

Estrogens are known as steroid hormones affecting the brain in many different ways and a wealth of data now document effects on neurogenesis. Estrogens are provided by the 
periphery but can also be locally produced within the brain itself due to local aromatization of circulating androgens. Adult neurogenesis is described in all vertebrate species examined so far, but comparative investigations have brought to light differences between vertebrate groups. In teleost fishes, the neurogenic activity is spectacular and adult stem cells maintain their mitogenic activity in many proliferative areas within the brain. Fish are also quite unique because brain aromatase expression is limited to radial glia cells, the progenitor cells of adult fish brain. The zebrafish has emerged as an interesting vertebrate model to elucidate the cellular and molecular mechanisms of adult neurogenesis, and notably its modulation by steroids. The main objective of this review is to summarize data related to the functional link between estrogens production in the brain and neurogenesis in fish. First, we will demonstrate that the brain of zebrafish is an endogenous source of steroids and is directly targeted by local and/or peripheral steroids. Then, we will present data demonstrating the progenitor nature of radial glial cells in the brain of adult fish. Next, we will emphasize the role of estrogens in constitutive neurogenesis and its potential contribution to the regenerative neurogenesis. Finally, the negative impacts on neurogenesis of synthetic hormones used in contraceptive pills production and released in the aquatic environment will be discussed.

\section{Keywords}

Zebrafish

Radial glial progenitor cells

Neurosteroids

Aromatase

Estradiol

Endocrine disruptors

\section{Introduction}

Despite the early establishment of the basic architecture of neural circuits, the adult brains of all vertebrates studied so far retain the capacity of remodeling in order to adapt their neuronal networks to environmental demands or to damages [1,2]. For the past twenty years, the dogma according to which the number of neurons is defined at birth without new formation and replacement in adulthood has been challenged by a series of research highlighting the capacity of the adult brain to generate new cells. The pioneering work of Altman and Das in 1960s reported the production of new neurons in a very limited number of brain areas in rodents [3]. This new concept of adult neurogenesis, initially rejected, was reinforced two decades later by the work of Nottebohm who has demonstrated that neurons 
were generated in the forebrain of adult birds and incorporated in the vocal control center, allowing the annual learning of new song [4]. Since the 1990s, with the introduction of new methods for labeling dividing cells, the existence of proliferative activity in the adult brain of mammals was indeed evidenced in confined regions such as the subventricular zone of the lateral ventricles and the dentate gyrus of the hippocampus [5-7] and findings strongly suggest that adult neurogenesis also takes place in the hypothalamus [8-10]. With the development of the thymidine analog 5-bromo2'-deoxyuridine (BrdU) incorporation technique as a tool to label newborn neurons, it clearly appeared that adult neurogenesis is not limited to mammals and birds but is a feature conserved across vertebrate evolution. The data generated with that simple and fast technique showed unambiguously that adult neurogenesis occurs in reptiles [11], amphibians [12, 13], fishes [14-17] and mammals notably in humans [18-20]. Currently, the adult neurogenesis concept is well accepted and defined as a complex and multistep process by which functional neurons are generated from resident neural stem/progenitor cells. In fact, neurogenesis encompasses the birth, the maturation and the migration of new neurons that integrate into existing neuronal networks [21, 22]. Although this phenomenon is common, comparative investigations have brought to light major differences between vertebrate groups in terms of neurogenic niches in the brain [23]. While the generation of new neurons is obvious in two main regions in mammals, the neurogenic potential in adult teleost fish is spectacular in many proliferative areas. This continuous production of new neurons in adulthood is notably supported by the persistence and abundance of radial glial cells (RGCs) [17, 24], known in mammals to serve as neural "stem" cells during embryonic neurogenesis $[25,26]$. Fish are also distinguished by their remarkable potential to regenerate their CNS from mechanical and chemical injuries by replacing damaged neurons such as shown in the cerebellum, the telencephalon and olfactory bulbs, the retina [27-32]. Indeed, a massive and transient increase in cell proliferation is observed in response to injuries applied to the brain and the spinal cord and newly generated neurons repopulate the wounded site allowing a complete regeneration of nervous tissue while the regenerative capacity of the adult mammalian brain is limited and the long-term survival of newborn cells is generally impaired [33]. The great neurogenic activity associated with the extraordinary repairing properties of the adult brain have made teleost fish valuable models to study and decipher mechanisms underlying adult neurogenesis in a constitutive or a regenerative context.

In mammals, a wealth of factors, notably neurotransmitters, growth factors and hormones, have been shown to modulate adult neurogenesis [34-38]. With respect to 
hormones, estradiol, is recognized as a major modulator of adult vertebrate neuronal plasticity $[39,40]$ and neurogenesis under physiological conditions and many data also demonstrated its neuroprotective actions in damaged brains [35, 41-47].

Estradiol may also play significant roles in teleost neurogenesis as the brain of fish is well known for harboring a high expression of aromatase, the only enzyme that catalyses the final step of estrogen biosynthesis. Aromatase is expressed in the brain of all vertebrates, but in teleost fish, the enzymatic activity is much higher than in mammal and bird. In addition, the three estrogen receptors are described in many brain areas of teleost fish [48-50].

In the last few years and for the above-mentioned reasons, the zebrafish has emerged as an interesting vertebrate model to elucidate the cellular and molecular mechanisms of adult neurogenesis, and notably its modulation by steroids, in normal and in reparative conditions. The main scope of this review is to summarize recently released information on the functional link between estrogens production in the brain and neurogenesis in fish with a particular focus on the zebrafish model. First, we will document the capacity of adult fish brain to produce steroids. We will present data demonstrating that RGCs could be an endogenous source of steroids and are directly targeted by local and/or peripheral steroids. We will next emphasize the role of estrogens in constitutive neurogenesis and its potential contribution to the regenerative neurogenesis. Finally, we will provide findings that point out the deleterious impacts on neurogenesis of synthetic hormones used in contraceptive pills production and released in the aquatic environment.

\section{The brain of adult zebrafish: a source of neurosteroids?}

\subsection{De novo neurosteroids synthesis}

While neurosteroids synthesis is widely documented in mammals, only few studies focused on de novo steroid synthesis in the brain of teleost fish [51-55] Such a feature raises the question of the origin, local and/or peripheral, of C19 androgens available for brain aromatization. Our laboratory recently demonstrated that the brain of adult zebrafish was able to de novo synthesize a wide variety of radiolabeled neurosteroids from $\left[{ }^{3} \mathrm{H}\right]$-pregnenolone. Among these locally-produced steroids, there are notably dehydroepiandrosterone (DHEA), androgens (i.e.: testosterone), estrogens (i.e.: estrone and $17 \beta$ estradiol), progesterone and derivatives $[51,55]$. Such results clearly evidence that $17 \beta$-hsd, $3 \alpha$ and $3 \beta$-hsd, cyp $17,5 \alpha-$ reductase and cyp19a1b (AroB) are expressed and biologically active in the brain of adult 
zebrafish. As no specific well-characterized antibodies are available, apart from AroB, and in order to determine the sites of production of neurosteroids in the zebrafish brain, in situ hybridization was performed for the main steroidogenic enzymes leading to estrogen synthesis (cypl1al -P450 SCC $^{-}, 3 \beta-h s d, c y p 17$ and cyp19alb). These experiments show that these steroidogenic enzymes are widely expressed in the whole brain, notably in the telencephalon, the preoptic area, the hypothalamus, the mesencephalon and the cerebellum. Moreover, they exhibit an overall similar pattern suggesting a potential co-expression, at least in some regions such as the hypothalamus. Thus, by performing cypl1al, $3 \beta$-hsd and cyp17 ISH followed by AroB immunohistochemistry, some steroidogenic enzymes transcripts were detected in AroB-radial glial cells, raising the question of the steroidogenic capacity of RGCs in zebrafish. In addition, the distribution of these main steroidogenic enzymes (apart from AroB) also strongly argues in favor of a neuronal expression. This is notably reinforced by the fact that $3 \beta$ HSD-like immunoreactivity was observed in neurons throughout the adult zebrafish brain [52]. Last but not least, steroidogenic enzymes expression in microglia and oligodendrocytes is not excluded, but it would require further investigations. Together, all these results show that the brain of adult zebrafish is a true steroidogenic organ, RGCs being a source of neurosteroids $[51,55,56]$, and raise the question of the targets of such steroids in the brain as well as their functions.

\subsection{Aromatase and radial glial cells}

Cytochrome P450 aromatase (aromatase), the rate-limiting enzyme that transform C19 androgens into estrogen, is described in the gonads and the brain of all vertebrates species studied so far, with a broader distribution in mammals [57]. Strikingly, when compared to other vertebrates and especially to mammals, the brain of adult fish exhibits an exceptionally high aromatase activity in anterior regions such as olfactory bulbs, telencephalon, preoptic area and hypothalamus $[48,58,59]$. The cyp19al genes, which encode aromatase, are highly conserved throughout vertebrate lineages but their expressions are driven by different regulatory mechanisms. In the mammalian genome a single cyp19al gene has been characterized (except in the pig) and its expression is driven by the use of distinct tissuespecific promoters and alternative splicing [60, 61]. As a result of teleost specific whole genome duplication [62], two cyp19a1 genes, cyp19ala and cyp19a1b, have been identified in most fish, except in the Japanese and European eel [63, 64]. As evidenced in a growing number of teleost species, including the zebrafish, those two genes encode different enzyme isoforms, aromatase A (AroA, produced by the cyp19ala gene), which is mostly described in 
the gonads and aromatase B (AroB, the product of the cyp19alb gene), which is strongly expressed in the brain [65-69]. Pioneering investigations on the localization of AroB have been first undertaken in the brain of goldfish by the group of Callard [70]. In this study, very few aromatase-positive cells were detected and displayed a neuronal phenotype. The small number of labeled cells and the fact that this antibody was raised against human aromatase now suggest that these results were artifactual. Since Forlano et al. work until the most recent publications in fish [71], the development of homologous and specific molecular tools such as cyp 19alb riboprobes and AroB antibodies has revealed in many teleost species a high number of AroB-expressing cells in ventricular position in the forebrain and midbrain, consistent with the strong aromatase enzymatic activity [64, 68, 71-73]. In zebrafish, cyp19alb messengers are strongly expressed along the ventricles in the olfactory bulbs, telencephalon, preoptic area, hypothalamus, thalamus and optic tectum [74]. Of particular interest is the fact that cyp19a1b mRNAs are also detected away from the ventricular cavities, suggesting their transport far from the cell bodies in the cytoplasmic extensions [51, 74]. Using specific zebrafish AroB-antibodies developed in our laboratory, a strong immunohistochemical labeling is visualized in cells bordering the ventricles, perfectly matching with the distribution of AroB mRNA [17, 74, 75]. The radial glial nature of AroB-expressing cells is clearly evidenced by their typical morphology (Figure 1A-1B), namely small cells body close to the ventricular cavities and long radial cytoplasmic processes underlining the surface of the brain $[17,75]$. In addition to their specific morphology, the radial glial identity is demonstrated by the fact that AroB staining is never colocalized with neuronal markers such as $\mathrm{Hu}$ or acetylated-tubulin [17]. Moreover, convincing double-immunolabeling with AroB antibodies and radial glial cells markers such as GFAP, BLBP and $\mathrm{S} 100 \beta[17,76,77]$ reinforced the fact that AroB expression is restricted to RGCs. The radial identity of cells expressing aromatase has been attested in fish and now, it appears clearly that in these species, RGCs are the primary source of aromatase in the brain $[64,71,72,78]$ while in mammals and birds, aromatase expression is confined to neurons under normal physiological conditions [79, 80]. Data recently obtained in our laboratory demonstrated that in amphibian, aromatase expression is restricted to neurons during development as in adulthood [81]. In adult zebrafish, we did not observed sexual dimorphism in the expression of AroB (transcripts and protein) while in medaka, females exhibit a stronger periventricular expression in several regions, in particular the optic tectum [73].

\subsection{Radial glial cells in zebrafish: a target of steroids?}


First of all, estrogens can act through three zebrafish nuclear estrogen receptors encoded by esr 1 (ER $\alpha)$, esr $2 a(\mathrm{ER} \beta 2)$ and esr2b (ER $\beta 1)$ genes. These receptors are widely expressed in the brain of zebrafish, in both larvae and adults [50, 51, 74, 75, 82]. In adults, esr 1 , esr $2 a$ and $e s r 2 b$ are mainly expressed in the subpallium, the anterior and posterior part of the preoptic area, in the anterior, mediobasal and caudal hypothalamus. Interestingly, they exhibit an overall similar pattern with some specific differences suggesting respective roles of these receptors in the estrogenic modulation of cell signaling and physiology. In fact, in the zebrafish brain, esr were originally described to be expressed in neurons and also along the ventricular layer $[74,75]$. In vivo and in vitro results also showed that cyp19alb expression is driven by ERs through an estrogen responsive element (ERE) on the cyp 19alb promoter [75, 82]. Together, these data strongly argue for esr expression in AroB positive RGCs, and recent experiments tend to confirm a weak esr2b expression in AroB-positive RGCs [83]. Estrogens could also exert their effect through the binding with a membrane estrogen receptor called GPR30 or Gper. This membrane receptor corresponds to a G-protein-coupled receptor. Few years ago, gper expression was reported in parenchymal cells and also in cells lining the ventricles of adult zebrafish, suggesting its expression in RGCs [84]. Estradiol treatments on acute brain slices of cyp19alb-GFP transgenic zebrafish line results in a rapid modulation of RGCs and parenchymal cells activities, revealed by calcium imaging [85]. Consequently, it appears that estrogens could target directly or indirectly a wide variety of cell-type and notably RGCs, and probably modify their functions.

In addition, in zebrafish and probably in other species, progesterone and progesterone derivatives may also act directly on RGC. In zebrafish, there is a unique nuclear progesterone receptor (Pgr), that actively binds progesterone (P), 17-hydroxy-P, dihydro-P, and 4-pregnen17,20 $\beta$-diol-3-one [86, 87], or membrane progestin receptors $\mathrm{mPR} \alpha, \beta$ and $\gamma$ [88]. In the brain of zebrafish, Pgr is expressed in neurons and RGCs, these latter exhibiting a significantly stronger Pgr staining, suggesting that RGCs could be preferential targets for progestagens [89]. We also evidenced that 17ß-estradiol up-regulates Pgr expression in the brain of both larvae and adult fish [89]. Similarly, inhibition of estrogen synthesis by an aromatase inhibitor (ATD) results in a significant reduction of $p g r$ expression in the brain of adult zebrafish [89]. Such an estrogenic regulation of $p g r$ expression is further reinforced by a recent transcriptomic analysis showing that $p g r$ is an estrogen target gene in zebrafish [90]. Concerning membrane progestin receptors, their roles and expression are poorly documented in the central nervous system [88]. However, taken together these data highlight the fact that progestagens could also impact cell functions of RGCs as well as neurons. 


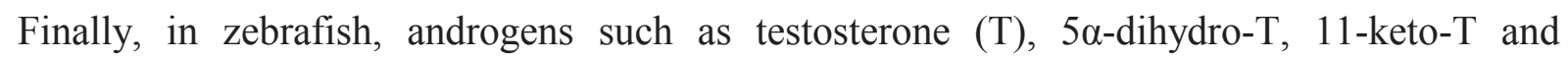
androstenedione can exert their effects through androgen receptor (AR) [91]. In the brain of adult zebrafish, ar transcripts appeared to be expressed in parenchymal cells [92]. In addition, ar expressing-cells were also observed in cells lining the ventricles of the preoptic area, the hypothalamus and also of the periglomerular gray zone of the optic tectum [92], suggesting expression in RGCs. Further investigations combining ISH and RGCs markers immunohistochemistry would be required for testing this assumption.

Consequently, the brain of adult zebrafish appears to be both a source and a target of steroids. Peculiarly, RGCs express a wide variety of steroidogenic enzymes and are also targeted by estrogens, progestagens and probably androgens. Thus, steroids could impact on the RGCs behavior and neurogenic vs. gliogenic activity and cell-cycle kinetics.

\section{Aromatase-expressing radial glial cells are progenitor cells in adult zebrafish.}

As mentioned above, in all teleost fish studied so far, AroB expression is strictly localized in RGCs. The zebrafish is certainly the best-documented species regarding AroB expression in RGCs as shown by studies based on in situ hybridization, immunohistochemistry and transgenic zebrafish expressing GFP under the promoter of cyp19alb gene $[17,74,75,77]$. In mammals, RGCs appear at the onset of neurogenesis. They were first described as cells providing guidance for newborn cells, but their role has been extended and it is now well established that these cells also divide and contribute to the embryonic neurogenesis in many brain regions [26, 93-96]. In adulthood, RGCs progenitors mostly disappeared in the brain of mammals, but some persist in restricted neurogenic areas such as the subgranular zone of the dentate gyrus of the hippocampus [96, 97]. In order to determine what roles RGCs encompass in teleost fish, we performed BrdU-labeling experiments with adult zebrafish. When zebrafish are sacrificed short time after the onset of BrdU treatment (12 or 24 hours), many dividing cells are observed at the edge of ventricles while no BrdU-staining is observed in the parenchyma $[16,17,98]$. When male and female were compared, no obvious differences were found in the ventral telencephalon, in the preoptic area and in the ventromedian hypothalamus [17]. However, more recent data showed that the dorsal telencephalon and the thalamus exhibited higher level of proliferating cells in females while in the dorsal part of the hypothalamus the quantity of cycling cells is higher in males [99]. Our data clearly shown for the first time that some of the dividing cells along the ventricles correspond to AroB-RGCs, which demonstrate that in fish as in mammals, RGCs 
are capable to generate new cells and display progenitor properties (Figure 1C-1E) [17, 100]. At longer survival times ( 5 to 45 days), Brdu-positive cells are seen at the ventricular surface, but many are also described away from the ventricle (Figure 1F) and interestingly in close contact with AroB-positive radial extensions, indicating that new-generated cells migrate laterally deeper in the parenchyma by using RGCs processes as a guidance support [17]. While some newborn cells move away from their birthplace, others in the subventricular layer appear to retain mitotic activity as evidenced by double BrdU/PCNA (a marker of proliferation) [17]. Finally, when zebrafish are sacrificed long time after BrdU exposure (30 days), we demonstrated by performing double staining with $\mathrm{BrdU}$ and $\mathrm{Hu}$ and acetylatedtubulin (two known neuronal markers) that new-generated cells moving away from the ventricles differentiate into neurons in many regions of the forebrain (Figure 1H-1J) [17]. More caudally, in the caudal part of the hypothalamus, a structure that concentrates numerous dopaminergic and serotoninergic neurons, we have shown that AroB-RGCs are also local source of new-generated cells and some of them differentiate into serotoninergic neurons (Figure 1G) [100]. However, presently, we cannot claim that all newborn born cells in the brain of adult zebrafish differentiate into neurons and we cannot rule out the possibility that some of those new cells become glial cells or undergo apoptotic process [101].

\section{Estrogens effects on constitutive and reparative neurogenesis in the adult zebrafish.}

Estrogens are recognized as major factors orchestrating the establishment of brain circuitry during development. Powerful effects on brain plasticity are also described in adulthood in basal condition and data in mammals have shown that estradiol contributes to neurogenic activity and modulates processes such as proliferation, migration and apoptosis of new-generated cells $[35,43,102-105]$. Several studies have pointed to a role of estradiol in brain repair processes following injury. The neuroprotective effects of estradiol would be to stimulate neurogenesis and to reduce apoptosis pathways [106-109]. The massive induction of aromatase mRNA and protein at the lesion site corroborates the role of estradiol in neuroprotection. Interestingly, while under physiological condition aromatase is mostly restrained to neurons, de novo expression is reported after lesions in reactive astrocytes surrounding the injury site in mammals and in radial glial cells facing the lesion in birds [45, 110-112]. The data from mammals and birds regarding estrogens and adult brain plasticity in physiological and reparative conditions raised the question of the close relationships between the strong and restricted expression of AroB in RGCs progenitors in fish under physiological 
conditions. By manipulating the level of circulating estradiol, we investigated whether the sustained neurogenesis of adult zebrafih brain is closely related to the production of estradiol in RGCs. In a first set of experiments, adult zebrafish have been exposed with the aromatase inhibitor ATD (1,4,6-Androstatrien-3,17-dione). As expected, the treatment with ADT (10${ }^{6} \mathrm{M}$ ) strongly reduced cyp19a1b expression and completely blocked its brain enzymatic activity. The proliferative activity was then checked with PCNA immunohistochemistry and surprisingly, even if no significant difference could be evidenced, all ATD-treated animals exhibited more PCNA-positive cells than control zebrafish in the anterior part of the brain, notably at the junction between the olfactory bulb and the telencephalon, in the preoptic area and in the mediobasal hypothalamus [32]. As the data obtained in mammals mainly emphasized the stimulatory effects estradiol on neurogenesis, our results were somewhat surprising and thus we used a complementary approach. Male adult zebrafish were treated with ICI $182,780\left(10^{-7} \mathrm{M}\right)$, an antagonist of nuclear estrogen receptors, during 48 or 54 hours. As the regulation of AroB expression is estrogen-dependent [75, 113], cyp19alb gene expression is significantly decreased at the end of ICI 182,780 exposure. In agreement with the results obtained with ATD, the quantification of the number of PCNA-labeled cells revealed a significant increase in the proliferative activity at the olfactory bulbs/telencephalon junction and in the mediobasal hypothalamus at 54 hours but not at 48 hours [32]. On the contrary, the treatment of zebrafish with $17 \beta$ estradiol $\left(10^{-7} \mathrm{M}\right)$ for 100 hours is associated with a significant decrease in the number of nuclei stained with the PCNA antibody at the junction of the olfactory bulbs and telencephalon, the periventricular pretectal nucleus and the mediobasal hypothalamus, a shorter treatment (48 hours) does not affect proliferation in these regions [32]. Taken together, these data are consistent and indicate that in fish, under our experimental conditions (time of exposure, concentration, region considered), estradiol inhibits rather than stimulates cell proliferation. As newborn cells move laterally along the radial glial cytoplasmic extension, we decided to investigate the impact of estradiol exposure on migration processes. In fish, exposure to $17 \beta$ estradiol $\left(10^{-7} \mathrm{M}\right)$ inhibits the migration of BrdU-labeled cells (Figure 2A-2B) but the effect is time and region-dependant, ie the migration is inhibited after 14 days of exposure in the ventral hypothalamus while 28 days of treatment are required to observe a significant inhibition at the junction of the olfactory bulbs/the telencephalon [32]. Cell survival was also slightly decreased at the junction between the olfactory bulbs after long-term treatment with estradiol, but these results requires further investigation [32]. Interestingly, the role of estradiol in neurogenesis has been addressed in 
adult female zebrafish and, as in male, $17 \beta$ estradiol induces a region-specific decrease in the number of cycling cells especially in telencephalic, hypothalamic and cerebellar areas [114]. In order to highlight the potential role of estradiol in regenerative neurogenesis, we have developed a model of mechanical lesion of the telencephalon. As described in previous papers, a very significant increase in proliferation activity is observed in the injured telencephalon compared to the undamaged telencephalic hemisphere $[29,30,32,115,116]$. The rise in the number of PCNA-positive cells is first apparent in the parenchyma surrounding the lesion site $24 \mathrm{~h}-48 \mathrm{~h}$ after the lesion. At this time, parenchymal proliferating cells have been identified as oligodendrocytes and microglial cells [29]. The proliferative activity gradually disappeared in the parenchyma while 5-7 days after injury, more and more PCNA-labeled cells massively concentrated in ventricular layer [29, 32]. The nature of cycling cells has been determined with antibodies directed against RGC markers (AroB, BLBP, GFAP, S100ß), neural progenitor markers (Sox2, NESTIN) and neuroblasts (PSANCAM). At this stage, most of periventricular proliferating cells correspond to RGCs expressing BLPB/GFAP/S100ß but, surprisingly, not AroB [29, 32, 117]. Unexpectedly, cyp 19a1b mRNA amount dropped in the damaged telencephalon immediately after the wound and the decrease remained noticeable even 7 days after the lesion when ventricular cells start to proliferate very actively. This inverse relationship is fully consistent with the results pointing out an inhibitory role of estradiol in physiological neurogenesis [32]. Interestingly, while AroB-expressing cells have never been observed in the parenchyma under normal condition, 3 days after the damage, AroB is detected in cells near the lesion site (Figure 2C$2 \mathrm{H})$ [32]. The identity of these de novo AroB-synthesizing cells is not known presently and further investigations are required. In order to go deeper inside the relationship between estradiol and the increase of proliferative activity in this context of reparative neurogenesis, stab wounded zebrafish were treated with estradiol or with ICI during 2 or 7 days. These treatments did not impact the injury-induced proliferation [32]. However, estradiol effects on migration, differentiation and survival of newborn cells have not been studied and cannot therefore be excluded.

Altogether, those results support the existence of a negative control exerted by estradiol on neurogenesis processes that takes place in the adult brain of zebrafish. As described above, under physiological conditions, estradiol exerts differential effects on proliferation, migration and survival of new-generated cells, depending on the length of the treatment, the concentration used and the region considered. The effects of estradiol in 
regenerative situations are presently incompletely studied and need more research that is currently in process.

\section{Adverse effects of endocrine disruptors during early neurogenesis in zebrafish.}

As described above, four different estrogen receptors (the three nuclear isoforms and the membrane receptor) are expressed in the adult brain of zebrafish. To follow the onset of estrogen receptors expression during embryogenesis, detailed studies based on RNA protection assay, real-time PCR and whole mount in situ hybridization have been performed [118-121]. These studies reported that maternally inherited estrogen receptors were detected early during the development. When embryonic transcription activity starts, esr 1 (ER $\alpha)$, esr $2 a$ (ER $\beta 2)$, esr2b (ER $\beta 1)$ and gper genes expression dramatically increased from 24 hours postfertilization (hpf) to $48 \mathrm{hpf}[119,121]$. Interestingly, a significant rise in cyp 19alb expression was also obvious during this period, in parallel to that observed for the estrogen receptors $[65$, 119]. Although esrl expression is detected by PCR between 24 and 48 hpf, esrl messengers were not detectable by in situ hybridization until 14 days post-fertilization. At this time, positive cells were observed in the ventral telencephalon and in the hypothalamus. The brain expression of esr $2 a$ and esr $2 b$ is clearly visible at $36 \mathrm{hpf}$ and increases between 48 and $60 \mathrm{hpf}$ in the forebrain and in the hypothalamus [119]. Whole mount in situ hybridization revealed that gper expression in the brain is detected after $18 \mathrm{hpf}$ and is obvious at $36 \mathrm{hpf}$ in the diencephalon, the midbrain and the mid-hindbrain boundary [122]. All estrogen receptors are doubtless fully functional at these stages of development as demonstrated by several studies. Using the cyp19a1b-GFP or wild type embryos, we have shown that GFP or AroB is strongly induced by estradiol in RGCs at $24 \mathrm{hpf}$, evidencing the functionality of estrogen receptors at early stages of development $[75,119]$. The strong increase in basal AroB expression at $24 \mathrm{hpf}$ relies on estrogen receptors activation because treatment of zebrafish embryos with ICI 182780 strongly reduced the AroB expression rise [119] and it has been shown with the use of morpholino knock-down technology of the three nuclear receptors isoforms that the AroB expression is specifically induced through ER $\beta 2$ receptors [123]. Knock-down experiments with Gper specific morpholinos induce profound alterations of apoptosis and proliferation that lead to morphological defect of the developing brain [122].

For several years now, there has been increasing concern about the deleterious impacts of many natural or synthetic molecules released in the environment on the development of aquatic species. Some of these molecules may interfere with the signalling pathways of sex 
steroids [124]. Using one of the property of cyp19alb-GFP transgenic zebrafish (ie the high sensitivity of the gene to estrogens), Brion et al., have screened the estrogenic activities of 45 different chemical compounds and demonstrated that half of them stimulate GFP fluorescence in larvae [124].

For example, this is the case for compounds such as Bisphenol A (BPA) that is commonly found in food containers and receipt tickets. An increasing number of studies pointed out the deleterious impact of BPA on zebrafish central and peripheral developmental processes. Alterations of heart morphology, skeletal muscles organizations have been described in early-life BPA-treated zebrafish [125-128]. A recent study showed that zebrafish embryos exposed to BPA accumulate lipids, suggesting a role of BPA in the onset of overweight and obesity [129]. Centrally BPA treatments elicit an upregulation of AroB expression in zebrafish larvae [130,131], an estrogenic effect mediated by estrogen receptor binding and transcriptional activation [124]. BPA has been shown to impair the early brain regionalization processes as evidenced by an inappropriate neuronal markers expression during zebrafish embryogenesis [132] and BPA exposure has been associated with an increase of precocious hypothalamic neurogenesis [133].

Ethinylestradiol (EE2) was until recently the main compound of the contraceptive pill. The above-mentioned data (i.e. estradiol effects on adult neurogenesis, functionality of estrogen receptors at the onset of the brain development) raised the question of the alterations induced by such molecules on early developmental stages, which could be influenced by many exogenous factors and the subsequent impacts in adulthood physiology. Studies dedicated to the impacts of EE2 in the brain of fish are very scarse. When larvae are exposed to EE2, the early development of the forebrain GnRH neurons circuitry is impaired with an increase in the number of GnRH neurons, a reduction in the size of their soma and a modification of their migration [134, 135]. Taking advantage of the cyp19alb-GFP transgenic zebrafish line (GFP expression restricted to RGCs and the strong susceptibility of the cyp 19a1b promoter to estrogens), it has been shown that EE2 were approximately 50 times more potent than estradiol to induced fluorescence in RGCs of zebrafish larvae treated during 5 days [124]. Recent exposure experiments (6 days) performed in our laboratory showed that low concentrations of EE2 (EE2 at $10^{-11} \mathrm{M}, 10^{-10} \mathrm{M}, 10^{-9} \mathrm{M}$ ) impaired the development of larvae and EE2-treated animals were smaller in size than the controls (Figure 3A). Quantitative PCR assays carried out on RNA extracts isolated from the head of EtOH or EE2treated zebrafish revealed that the transcripts level for AroB were dose-dependently and significantly increased (Figure $3 \mathrm{~B}$ ) and expression of PCNA tends to decrease but the 
difference were not significant (Figure 3C). Even if those recent data need to be reinforced and complete with neuroanatomical approaches, they strongly suggest that EE2 disrupts the proliferative activity in the brain of 6 days treated-larvae, an effect that is consistent with the inhibitory action of estradiol described in the brain of adult zebrafish.

\section{Conclusion}

Zebrafish provides a unique model for studying the impact of steroids on neurogenesis and also the potential effects of endocrine disruptors on this critical mechanism. Obviously, fish differ from other vertebrates in several respects that are probably linked to each other. The most intriguing feature certainly is the massive expression of aromatase in RGCs, the function of which is still unclear in terms of evolution and adaptation. To our knowledge, there is no equivalent situation in other vertebrates where aromatase is expressed mostly in neurons and does not seem to be so sensitive to estradiol. Our current hypothesis is that, given the high neurogenic activity of the brain of adult fish and the fact that fish do not perform somatic growth and gonadal growth at the same time, cell proliferation has to be turned down when there is a high demand of energy, i.e. when fish are entering gametogenesis. In fish this process is accompanied by a rise in steroid production and either directly from the gonad or indirectly through aromatization of androgens. In any case, what this shows is that sex steroids certainly have the potential to affect neurodevelopment in fish, with the consequence that endocrine disruptors with hormone mimetic effects may also disrupt the neurogenic activity.

\section{Acknowledgments}

The ANR PROOF (CES-2008-11), the Post-Grenelle grant NEMO and the TC2N Program supported this research.

\section{Legends}

Figure 1: Aromatase B and neurogenesis in the brain of adult zebrafish.

A and B: AroB-positive RGCs in the preoptic area (POA) and at the level of the nucleus of the posterior recess (NPR). (A) In the POA, RGCs soma is closed to the ventricle (V). RGCs send a short cytoplasmic extension toward the ventricle and a long one in the direction of the 
brain surface (arrow head). (B) At the level of the NPR, AroB-RGCs surrounding the posterior recess (pr) are distant from the ventricular cavity, in contrast with most anterior regions of the brain. RGCs exhibit long cytoplasmic processes (arrow head) that form endfeet (stars) and establish a continuous barrier running along the ventricle. Scale bar: A, $100 \mu \mathrm{m}$ and $\mathrm{B}, 50 \mu \mathrm{m}$.

C, D and E: Immunohistochemistry for AroB (red) and BrdU (green, 12 hours of treatment) at the level of the telencephalon (Tel) in a male sacrificed at the end of Brdu treatment. The picture $\mathrm{E}$ (merge from $\mathrm{C}$ and $\mathrm{D}$ ) demonstrates the capacity AroB-positive RGCs to incorporate BrdU and divide. Scale bar: $50 \mu \mathrm{m}$.

F: Double staining at the junction between the olfactory bulb (OB) and the telencephalon (Tel) for BrdU (red) and AroB (green) 30 days after a BrdU treatment (48 hours). A large number of BrdU-nuclei move away from the ventricle (V). Some BrdU nuclei are retained along the ventricle where AroB-positives RGCs are located (arrows). Scale bar: $100 \mu \mathrm{m}$.

G: Transverse section at the level of the nucleus of the posterior recess (NPR), showing that 30 days after BrdU treatment (48 hours), serotonin neurons (green labeling) are labeled with BrdU (red labeling) (arrows). Scale bar: $25 \mu \mathrm{m}$.

H, I and $\mathbf{J}$ : Photographs taken at the junction between olfactory bulbs and telencephalon (Tel) of a male treated with BrdU (48 hours) and sacrificed 30 days after the treatment. Several Acetylated-tubulin positive cells (green) exhibit a BrdU-labeled nucleus (red) (arrows). Scale bar: $50 \mu \mathrm{m}$.

\section{Figure 2: Estradiol and neurogenesis in constitutive and reparative conditions.}

A and B: BrdU (12 hours exposure) labeling at the junction between olfactory bulbs (OB) and telencephalon (Tel) in a male treated with EtOH (A) or with estradiol (E2, B) $\left(10^{-7} \mathrm{M}, 28\right.$ days). Animals were sacrificed immediately after E2-treatment (28 days). Estradiol inhibits the migration of newborn cells that tends to stay along the ventricle. Scale bar: $25 \mu \mathrm{m}$.

C, D, E and F, G, H: transverse sections showing AroB immunohistochemistry (C, F) 72 hours after telencephalon injury. Nuclei have been labeled with DAPI (D, G). (C, D and E: adult male $\mathrm{N}^{\circ} 1$; F, G and $\mathrm{H}$ : adult male $\mathrm{N}^{\circ} 2$ ). Some parenchymal cells express AroB (arrows) following the injury. Scale bar: $50 \mu \mathrm{m}$.

Figure 3: Impacts of EE2 treatment on the zebrafish larvae. 
Animals were kept, handled and killed in agreement with the European Union regulation concerning the use and protection of experimental animals (Directive 86/609/EEC). Zebrafish embryos were divided into four different groups $(\mathrm{N}=80)$. Three groups were exposed from day 1 to day 7 at different concentrations of ethinylestradiol (EE2, $10^{-11} \mathrm{M}, 10^{-10} \mathrm{M}, 10^{-9} \mathrm{M}$ ) according to the protocol of Diotel et al. and Mouriec et al. [89, 119]. The control group was exposed for the same time to the solvent (ethanol, EtOH). Six independent experiments have been performed.

A: Size of larvae at the end of EE2 exposure. Zebrafish of each experimental group (30 animals) have been measured. The size of larvae is expressed as means $+/$ - standard error of the mean (SEM) of 2 independent experiments. Statistical analysis is performed with the nonparametric Kruskal-Wallis test. When $\mathrm{p}$ value is below 0,05 the difference between groups was considered to be statistically significant. a: versus EtOH; b: versus EE2 $10^{-11} \mathrm{M}$; c: versus EE2 $10^{-10} \mathrm{M}$.

B and C: Fold induction of cyp19alb (B) and pcna (C) gene expression in control fish $(\mathrm{EtOH})$ and in EE2 treated-fish. RNA extraction (60 heads pooled per condition), cDNA synthesis and SYBR Green quantitative PCR was performed following the protocol described in Pellegrini et al., 2007. A relative quantification of cyp19alb and pcna genes was made with efl as standard gene. The delta/delta CT method was used to determine the relative expression. Results represent the means +/- standard error of the mean (SEM) of 6 independent experiments. Statistical analysis is performed with the non-parametric KruskalWallis test. When $\mathrm{p}$ value is below 0,05 the difference between groups was considered to be statistically significant. a: versus EtOH.

The primers used were: EF1 (fw) 5'-AGCAGCAGCTGAGGAGTGAT-3' ; (rev) 5'-CCGCAT TTGTAGATCAGATGG-3'; AroB (fw) 5'-TCGGCACGGCGTGCAACTAC-3'; AroB (rev) 5'-CATACCTATGCATTGCAGACC-3' ; PCNA (fw) 5'- CTCACAGACCAGCAACGTCG3'; (rev) 5'- GGACAGAGGAGTGGCTTTGG- 3'. 

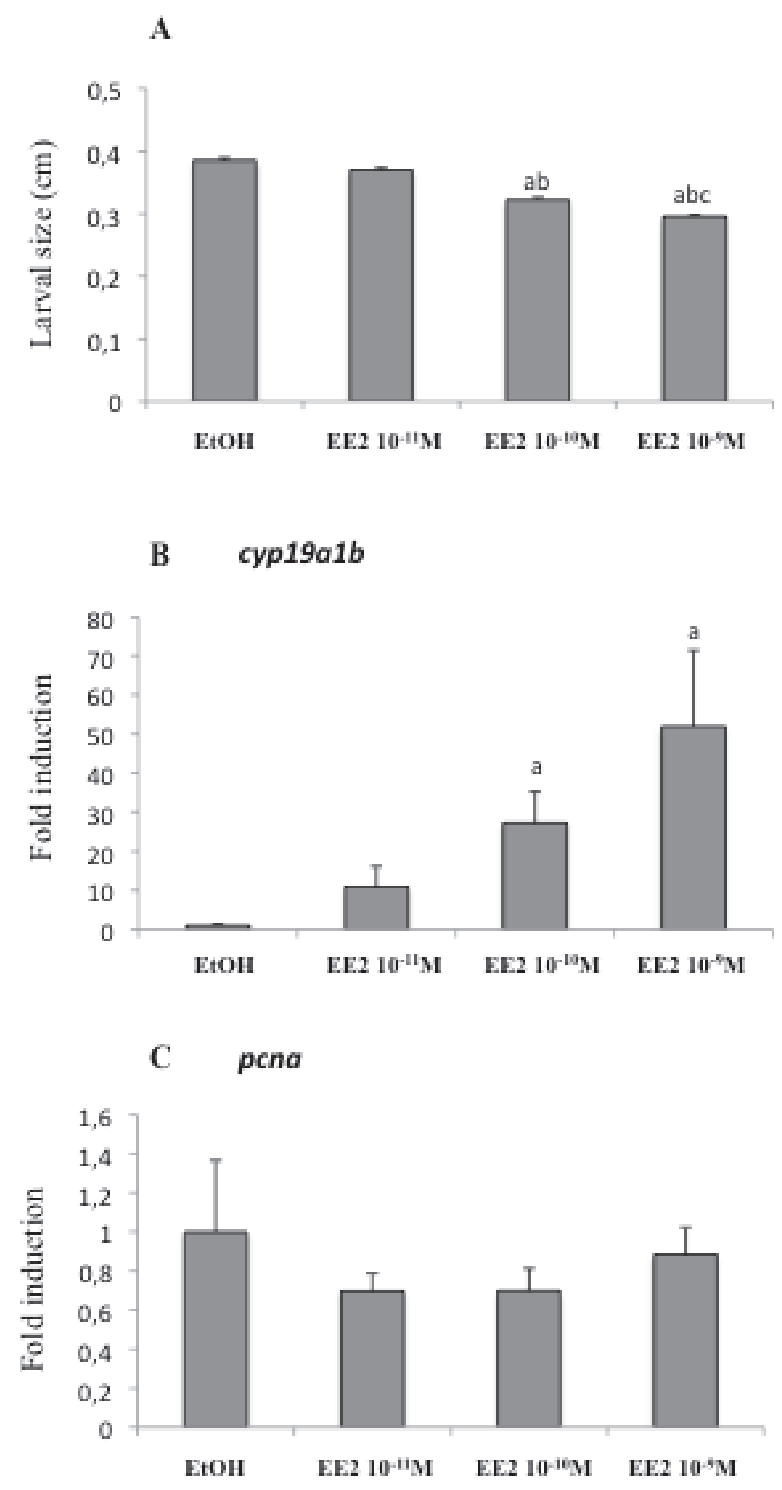

Figure 3 black and white (1 colum)

\section{References}


[1] H. Grandel, M. Brand, Comparative aspects of adult neural stem cell activity in vertebrates, Development genes and evolution, 223 (2013) 131-147.

[2] L. Dimou, M. Gotz, Glial cells as progenitors and stem cells: new roles in the healthy and diseased brain, Physiological reviews, 94 (2014) 709-737.

[3] J. Altman, G.D. Das, Autoradiographic and histological evidence of postnatal hippocampal neurogenesis in rats, The Journal of comparative neurology, 124 (1965) 319-335.

[4] S.A. Goldman, F. Nottebohm, Neuronal production, migration, and differentiation in a vocal control nucleus of the adult female canary brain, Proceedings of the National Academy of Sciences of the United States of America, 80 (1983) 2390-2394.

[5] M.B. Luskin, Restricted proliferation and migration of postnatally generated neurons derived from the forebrain subventricular zone, Neuron, 11 (1993) 173-189.

[6] C. Lois, A. Alvarez-Buylla, Proliferating subventricular zone cells in the adult mammalian forebrain can differentiate into neurons and glia, Proceedings of the National Academy of Sciences of the United States of America, 90 (1993) 2074-2077.

[7] E. Gould, C.G. Gross, Neurogenesis in adult mammals: some progress and problems, The Journal of neuroscience : the official journal of the Society for Neuroscience, 22 (2002) 619-623.

[8] G.L. Ming, H. Song, Adult neurogenesis in the mammalian central nervous system, Annu Rev Neurosci, 28 (2005) 223-250.

[9] D.A. Lee, S. Blackshaw, Functional implications of hypothalamic neurogenesis in the adult mammalian brain, Int J Dev Neurosci, 30 (2012) 615-621.

[10] M.V. Kokoeva, H. Yin, J.S. Flier, Neurogenesis in the hypothalamus of adult mice: potential role in energy balance, Science (New York, N.Y.), 310 (2005) 679-683.

[11] E. Font, E. Desfilis, M.M. Perez-Canellas, J.M. Garcia-Verdugo, Neurogenesis and neuronal regeneration in the adult reptilian brain, Brain, behavior and evolution, 58 (2001) 276-295.

[12] L.A. D'Amico, D. Boujard, P. Coumailleau, Proliferation, migration and differentiation in juvenile and adult Xenopus laevis brains, Brain research, 1405 (2011) 31-48.

[13] A.L. Polenov, V.K. Chetverukhin, Ultrastructural radioautographic analysis of neurogenesis in the hypothalamus of the adult frog, Rana temporaria, with special reference to physiological regeneration of the preoptic nucleus. II. Types of neuronal cells produced, Cell and tissue research, 271 (1993) 351-362.

[14] G.K. Zupanc, Adult neurogenesis and neuronal regeneration in the central nervous system of teleost fish, Brain Behav Evol, 58 (2001) 250-275.

[15] P. Ekstrom, C.M. Johnsson, L.M. Ohlin, Ventricular proliferation zones in the brain of an adult teleost fish and their relation to neuromeres and migration (secondary matrix) zones, The Journal of comparative neurology, 436 (2001) 92-110.

[16] B. Adolf, P. Chapouton, C.S. Lam, S. Topp, B. Tannhauser, U. Strahle, M. Gotz, L. BallyCuif, Conserved and acquired features of adult neurogenesis in the zebrafish telencephalon, Dev Biol, 295 (2006) 278-293.

[17] E. Pellegrini, K. Mouriec, I. Anglade, A. Menuet, Y. Le Page, M.M. Gueguen, M.H. Marmignon, F. Brion, F. Pakdel, 0. Kah, Identification of aromatase-positive radial glial cells as progenitor cells in the ventricular layer of the forebrain in zebrafish, The Journal of comparative neurology, 501 (2007) 150-167.

[18] P.S. Eriksson, E. Perfilieva, T. Bjork-Eriksson, A.M. Alborn, C. Nordborg, D.A. Peterson, F.H. Gage, Neurogenesis in the adult human hippocampus, Nature medicine, 4 (1998) 1313-1317. 
[19] F.H. Gage, Mammalian neural stem cells, Science (New York, N.Y.), 287 (2000) 1433-1438.

[20] P.J. Bernier, J. Vinet, M. Cossette, A. Parent, Characterization of the subventricular zone of the adult human brain: evidence for the involvement of Bcl-2, Neuroscience research, 37 (2000) 67-78.

[21] L.C. Fuentealba, K. Obernier, A. Alvarez-Buylla, Adult neural stem cells bridge their niche, Cell Stem Cell, 10 (2012) 698-708.

[22] R. Schmidt, U. Strahle, S. Scholpp, Neurogenesis in zebrafish - from embryo to adult, Neural Dev, 8 (2013) 3.

[23] B.W. Lindsey, V. Tropepe, A comparative framework for understanding the biological principles of adult neurogenesis, Prog Neurobiol, 80 (2006) 281-307.

[24] B. Onteniente, H. Kimura, T. Maeda, Comparative study of the glial fibrillary acidic protein in vertebrates by PAP immunohistochemistry, The Journal of comparative neurology, 215 (1983) 427-436.

[25] A. Kriegstein, A. Alvarez-Buylla, The glial nature of embryonic and adult neural stem cells, Annu Rev Neurosci, 32 (2009) 149-184.

[26] S.C. Noctor, A.C. Flint, T.A. Weissman, W.S. Wong, B.K. Clinton, A.R. Kriegstein, Dividing precursor cells of the embryonic cortical ventricular zone have morphological and molecular characteristics of radial glia, The Journal of neuroscience : the official journal of the Society for Neuroscience, 22 (2002) 3161-3173.

[27] G.K. Zupanc, Neurogenesis and neuronal regeneration in the adult fish brain, J Comp Physiol A Neuroethol Sens Neural Behav Physiol, 192 (2006) 649-670.

[28] G.K. Zupanc, R.F. Sirbulescu, Teleost fish as a model system to study successful regeneration of the central nervous system, Current topics in microbiology and immunology, 367 (2013) 193-233.

[29] M. März, R. Schmidt, S. Rastegar, U. Strahle, Regenerative response following stab injury in the adult zebrafish telencephalon, Dev Dyn, 240 (2011) 2221-2231.

[30] V. Kroehne, D. Freudenreich, S. Hans, J. Kaslin, M. Brand, Regeneration of the adult zebrafish brain from neurogenic radial glia-type progenitors, Development (Cambridge, England), 138 (2011) 4831-4841.

[31] K. Skaggs, D. Goldman, J.M. Parent, Excitotoxic brain injury in adult zebrafish stimulates neurogenesis and long-distance neuronal integration, Glia, 62 (2014) 20612079.

[32] N. Diotel, C. Vaillant, C. Gabbero, S. Mironov, A. Fostier, M.M. Gueguen, I. Anglade, O. Kah, E. Pellegrini, Effects of estradiol in adult neurogenesis and brain repair in zebrafish, Horm Behav, 63 (2013) 193-207.

[33] G.K. Zupanc, R.F. Sirbulescu, Adult neurogenesis and neuronal regeneration in the central nervous system of teleost fish, Eur J Neurosci, 34 (2011) 917-929.

[34] L.A. Galea, M.D. Spritzer, J.M. Barker, J.L. Pawluski, Gonadal hormone modulation of hippocampal neurogenesis in the adult, Hippocampus, 16 (2006) 225-232.

[35] B.K. Ormerod, T.T. Lee, L.A. Galea, Estradiol initially enhances but subsequently suppresses (via adrenal steroids) granule cell proliferation in the dentate gyrus of adult female rats, J Neurobiol, 55 (2003) 247-260.

[36] M. Banasr, M. Hery, R. Printemps, A. Daszuta, Serotonin-induced increases in adult cell proliferation and neurogenesis are mediated through different and common 5-HT receptor subtypes in the dentate gyrus and the subventricular zone, Neuropsychopharmacology, 29 (2004) 450-460.

[37] A. Hurtado-Chong, M.J. Yusta-Boyo, E. Vergano-Vera, A. Bulfone, F. de Pablo, C. Vicario-Abejon, IGF-I promotes neuronal migration and positioning in the olfactory bulb 
and the exit of neuroblasts from the subventricular zone, Eur J Neurosci, 30 (2009) 742755.

[38] T.J. Schoenfeld, E. Gould, Stress, stress hormones, and adult neurogenesis, Exp Neurol, 233 (2012) 12-21.

[39] Y. Hojo, G. Murakami, H. Mukai, S. Higo, Y. Hatanaka, M. Ogiue-Ikeda, H. Ishii, T. Kimoto, S. Kawato, Estrogen synthesis in the brain--role in synaptic plasticity and memory, Molecular and cellular endocrinology, 290 (2008) 31-43.

[40] R.D. Brinton, Estrogen-induced plasticity from cells to circuits: predictions for cognitive function, Trends Pharmacol Sci, 30 (2009) 212-222.

[41] B.K. Ormerod, T.T. Lee, L.A. Galea, Estradiol enhances neurogenesis in the dentate gyri of adult male meadow voles by increasing the survival of young granule neurons, Neuroscience, 128 (2004) 645-654.

[42] C.A. Mazzucco, S.E. Lieblich, B.I. Bingham, M.A. Williamson, V. Viau, L.A. Galea, Both estrogen receptor alpha and estrogen receptor beta agonists enhance cell proliferation in the dentate gyrus of adult female rats, Neuroscience, 141 (2006) 1793-1800.

[43] O. Brock, M. Keller, A. Veyrac, Q. Douhard, J. Bakker, Short term treatment with estradiol decreases the rate of newly generated cells in the subventricular zone and main olfactory bulb of adult female mice, Neuroscience, 166 (2010) 368-376.

[44] L.M. Garcia-Segura, Aromatase in the brain: not just for reproduction anymore, Journal of neuroendocrinology, 20 (2008) 705-712.

[45] L.M. Garcia-Segura, F. Naftolin, J.B. Hutchison, I. Azcoitia, J.A. Chowen, Role of astroglia in estrogen regulation of synaptic plasticity and brain repair, J Neurobiol, 40 (1999) 574-584.

[46] Q.G. Zhang, R. Wang, H. Tang, Y. Dong, A. Chan, G.R. Sareddy, R.K. Vadlamudi, D.W. Brann, Brain-derived estrogen exerts anti-inflammatory and neuroprotective actions in the rat hippocampus, Molecular and cellular endocrinology, 389 (2014) 84-91.

[47] J.W. Gatson, J.W. Simpkins, K.D. Yi, A.H. Idris, J.P. Minei, J.G. Wigginton, Aromatase is increased in astrocytes in the presence of elevated pressure, Endocrinology, 152 (2011) 207-213.

[48] M. Pasmanik, G.V. Callard, Aromatase and 5 alpha-reductase in the teleost brain, spinal cord, and pituitary gland, General and comparative endocrinology, 60 (1985) 244-251.

[49] M.B. Hawkins, J.W. Thornton, D. Crews, J.K. Skipper, A. Dotte, P. Thomas, Identification of a third distinct estrogen receptor and reclassification of estrogen receptors in teleosts, Proceedings of the National Academy of Sciences of the United States of America, 97 (2000) 10751-10756.

[50] A. Menuet, E. Pellegrini, I. Anglade, O. Blaise, V. Laudet, O. Kah, F. Pakdel, Molecular characterization of three estrogen receptor forms in zebrafish: binding characteristics, transactivation properties, and tissue distributions, Biol Reprod, 66 (2002) 1881-1892.

[51] N. Diotel, J.L. Do Rego, I. Anglade, C. Vaillant, E. Pellegrini, H. Vaudry, O. Kah, The brain of teleost fish, a source, and a target of sexual steroids, Front Neurosci, 5 (2011) 137.

[52] H. Sakamoto, K. Ukena, K. Tsutsui, Activity and localization of 3beta-hydroxysteroid dehydrogenase/ Delta5-Delta4-isomerase in the zebrafish central nervous system, The Journal of comparative neurology, 439 (2001) 291-305.

[53] J.L. Do Rego, J.Y. Seong, D. Burel, J. Leprince, V. Luu-The, K. Tsutsui, M.C. Tonon, G. Pelletier, H. Vaudry, Neurosteroid biosynthesis: enzymatic pathways and neuroendocrine regulation by neurotransmitters and neuropeptides, Frontiers in neuroendocrinology, 30 (2009) 259-301. 
[54] G.V. Callard, M. Drygas, D. Gelinas, Molecular and cellular physiology of aromatase in the brain and retina, The Journal of steroid biochemistry and molecular biology, 44 (1993) 541-547.

[55] N. Diotel, J.L. Do Rego, I. Anglade, C. Vaillant, E. Pellegrini, M.M. Gueguen, S. Mironov, $\mathrm{H}$. Vaudry, O. Kah, Activity and expression of steroidogenic enzymes in the brain of adult zebrafish, Eur J Neurosci, 34 (2011) 45-56.

[56] L. Xing, M. Goswami, V.L. Trudeau, Radial glial cell: critical functions and new perspective as a steroid synthetic cell, General and comparative endocrinology, 203 (2014) 181-185.

[57] E.R. Simpson, M.S. Mahendroo, G.D. Means, M.W. Kilgore, M.M. Hinshelwood, S. Graham-Lorence, B. Amarneh, Y. Ito, C.R. Fisher, M.D. Michael, et al., Aromatase cytochrome P450, the enzyme responsible for estrogen biosynthesis, Endocr Rev, 15 (1994) 342-355.

[58] D. Goncalves, M. Teles, J. Alpedrinha, R.F. Oliveira, Brain and gonadal aromatase activity and steroid hormone levels in female and polymorphic males of the peacock blenny Salaria pavo, Horm Behav, 54 (2008) 717-725.

[59] R.J. Timmers, J.G. Lambert, J. Peute, H.G. Vullings, P.G. van Oordt, Localization of aromatase in the brain of the male African catfish, Clarias gariepinus (Burchell), by microdissection and biochemical identification, The Journal of comparative neurology, 258 (1987) 368-377.

[60] S.E. Bulun, S. Sebastian, K. Takayama, T. Suzuki, H. Sasano, M. Shozu, The human CYP19 (aromatase P450) gene: update on physiologic roles and genomic organization of promoters, The Journal of steroid biochemistry and molecular biology, 86 (2003) 219224.

[61] D. Silandre, C. Delalande, P. Durand, S. Carreau, Three promoters PII, PI.f, and PI.tr direct the expression of aromatase (cyp19) gene in male rat germ cells, J Mol Endocrinol, 39 (2007) 169-181.

[62] D. Steinke, S. Hoegg, H. Brinkmann, A. Meyer, Three rounds (1R/2R/3R) of genome duplications and the evolution of the glycolytic pathway in vertebrates, BMC Biol, 4 (2006) 16.

[63] I. Tzchori, G. Degani, A. Hurvitz, B. Moav, Cloning and developmental expression of the cytochrome P450 aromatase gene (CYP19) in the European eel (Anguilla anguilla), General and comparative endocrinology, 138 (2004) 271-280.

[64] S.R. Jeng, W.S. Yueh, Y.T. Pen, M.M. Gueguen, J. Pasquier, S. Dufour, C.F. Chang, O. Kah, Expression of aromatase in radial glial cells in the brain of the Japanese eel provides insight into the evolution of the cyp191a gene in Actinopterygians, PloS one, 7 (2012) e44750.

[65] M. Kishida, G.V. Callard, Distinct cytochrome P450 aromatase isoforms in zebrafish (Danio rerio) brain and ovary are differentially programmed and estrogen regulated during early development, Endocrinology, 142 (2001) 740-750.

[66] A. Tchoudakova, G.V. Callard, Identification of multiple CYP19 genes encoding different cytochrome P450 aromatase isozymes in brain and ovary, Endocrinology, 139 (1998) 2179-2189.

[67] X. Chang, T. Kobayashi, B. Senthilkumaran, H. Kobayashi-Kajura, C.C. Sudhakumari, Y. Nagahama, Two types of aromatase with different encoding genes, tissue distribution and developmental expression in Nile tilapia (Oreochromis niloticus), General and comparative endocrinology, 141 (2005) 101-115.

[68] P.H. Strobl-Mazzulla, N.P. Moncaut, G.C. Lopez, L.A. Miranda, A.V. Canario, G.M. Somoza, Brain aromatase from pejerrey fish (Odontesthes bonariensis): cDNA cloning, 
tissue expression, and immunohistochemical localization, General and comparative endocrinology, 143 (2005) 21-32.

[69] J.G. Patil, R.M. Gunasekera, Tissue and sexually dimorphic expression of ovarian and brain aromatase mRNA in the Japanese medaka (Oryzias latipes): implications for their preferential roles in ovarian and neural differentiation and development, General and comparative endocrinology, 158 (2008) 131-137.

[70] D. Gelinas, G.V. Callard, Immunolocalization of aromatase- and androgen receptorpositive neurons in the goldfish brain, General and comparative endocrinology, 106 (1997) 155-168.

[71] P.M. Forlano, D.L. Deitcher, D.A. Myers, A.H. Bass, Anatomical distribution and cellular basis for high levels of aromatase activity in the brain of teleost fish: aromatase enzyme and mRNA expression identify glia as source, The Journal of neuroscience : the official journal of the Society for Neuroscience, 21 (2001) 8943-8955.

[72] A. Menuet, I. Anglade, R. Le Guevel, E. Pellegrini, F. Pakdel, O. Kah, Distribution of aromatase mRNA and protein in the brain and pituitary of female rainbow trout: Comparison with estrogen receptor alpha, The Journal of comparative neurology, 462 (2003) 180-193.

[73] K. Okubo, A. Takeuchi, R. Chaube, B. Paul-Prasanth, S. Kanda, Y. Oka, Y. Nagahama, Sex differences in aromatase gene expression in the medaka brain, Journal of neuroendocrinology, 23 (2011) 412-423.

[74] E. Pellegrini, A. Menuet, C. Lethimonier, F. Adrio, M.M. Gueguen, C. Tascon, I. Anglade, F. Pakdel, O. Kah, Relationships between aromatase and estrogen receptors in the brain of teleost fish, General and comparative endocrinology, 142 (2005) 60-66.

[75] A. Menuet, E. Pellegrini, F. Brion, M.M. Gueguen, I. Anglade, F. Pakdel, O. Kah, Expression and estrogen-dependent regulation of the zebrafish brain aromatase gene, The Journal of comparative neurology, 485 (2005) 304-320.

[76] M. März, P. Chapouton, N. Diotel, C. Vaillant, B. Hesl, M. Takamiya, C.S. Lam, O. Kah, L. Bally-Cuif, U. Strahle, Heterogeneity in progenitor cell subtypes in the ventricular zone of the zebrafish adult telencephalon, Glia, 58 (2010) 870-888.

[77] S.K. Tong, K. Mouriec, M.W. Kuo, E. Pellegrini, M.M. Gueguen, F. Brion, O. Kah, B.C. Chung, A cyp19a1b-gfp (aromatase B) transgenic zebrafish line that expresses GFP in radial glial cells, Genesis, 47 (2009) 67-73.

[78] N. Diotel, Y. Le Page, K. Mouriec, S.K. Tong, E. Pellegrini, C. Vaillant, I. Anglade, F. Brion, F. Pakdel, B.C. Chung, O. Kah, Aromatase in the brain of teleost fish: expression, regulation and putative functions, Frontiers in neuroendocrinology, 31 (2010) 172-192.

[79] J. Balthazart, P. Absil, A. Foidart, M. Houbart, N. Harada, G.F. Ball, Distribution of aromatase-immunoreactive cells in the forebrain of zebra finches (Taeniopygia guttata): implications for the neural action of steroids and nuclear definition in the avian hypothalamus, J Neurobiol, 31 (1996) 129-148.

[80] J. Balthazart, G.F. Ball, New insights into the regulation and function of brain estrogen synthase (aromatase), Trends Neurosci, 21 (1998) 243-249.

[81] P. Coumailleau, O. Kah, Cyp19a1 (aromatase) expression in the Xenopus brain at different developmental stages, Journal of neuroendocrinology, 26 (2014) 226-236.

[82] K. Mouriec, J.J. Lareyre, S.K. Tong, Y. Le Page, C. Vaillant, E. Pellegrini, F. Pakdel, B.C. Chung, 0. Kah, I. Anglade, Early regulation of brain aromatase (cyp19a1b) by estrogen receptors during zebrafish development, Dev Dyn, (2009).

[83] E. Pellegrini, P. Coumailleau, O. Kah, N. Diotel, Aromatase and Estrogens: Involvement in Constitutive and Regenerative Neurogenesis in Adult Zebrafish, In 
Duncan K., eds. Estrogen Effects on Brain injury, Academical Press, Elsevier, , (2014) 5171.

[84] X. Liu, P. Zhu, K.W. Sham, J.M. Yuen, C. Xie, Y. Zhang, Y. Liu, S. Li, X. Huang, C.H. Cheng, H. Lin, Identification of a membrane estrogen receptor in zebrafish with homology to mammalian GPER and its high expression in early germ cells of the testis, Biology of reproduction, 80 (2009) 1253-1261.

[85] E. Pellegrini, C. Vaillant, N. Diotel, P. Benquet, F. Brion, O. Kah, Expression, regulation and potential functions of aromatase in radial glial cells of the fish brain, In Balthazart J., Ball G.F., eds. Brain aromatase, estrogens and behavior, Oxford University Press, Oxford; New york, (2013) 115-137.

[86] R.N. Hanna, S.C. Daly, Y. Pang, I. Anglade, O. Kah, P. Thomas, Y. Zhu, Characterization and expression of the nuclear progestin receptor in zebrafish gonads and brain, Biology of reproduction, 82 (2010) 112-122.

[87] S.X. Chen, J. Bogerd, A. Garcia-Lopez, H. de Jonge, P.P. de Waal, W.S. Hong, R.W. Schulz, Molecular cloning and functional characterization of a zebrafish nuclear progesterone receptor, Biology of reproduction, 82 (2010) 171-181.

[88] R.N. Hanna, Y. Zhu, Expression of membrane progestin receptors in zebrafish (Danio rerio) oocytes, testis and pituitary, General and comparative endocrinology, 161 (2009) 153-157.

[89] N. Diotel, A. Servili, M.M. Gueguen, S. Mironov, E. Pellegrini, C. Vaillant, Y. Zhu, O. Kah, I. Anglade, Nuclear progesterone receptors are up-regulated by estrogens in neurons and radial glial progenitors in the brain of zebrafish, PloS one, 6 (2011) e28375. [90] R. Hao, M. Bondesson, A.V. Singh, A. Riu, C.W. McCollum, T.B. Knudsen, D.A. Gorelick, J.A. Gustafsson, Identification of estrogen target genes during zebrafish embryonic development through transcriptomic analysis, PloS one, 8 (2013) e79020.

[91] A. Jorgensen, O. Andersen, P. Bjerregaard, L.J. Rasmussen, Identification and characterisation of an androgen receptor from zebrafish Danio rerio, Comp Biochem Physiol C Toxicol Pharmacol, 146 (2007) 561-568.

[92] D.A. Gorelick, W. Watson, M.E. Halpern, Androgen receptor gene expression in the developing and adult zebrafish brain, Dev Dyn, 237 (2008) 2987-2995.

[93] P. Rakic, Neuronal migration and contact guidance in the primate telencephalon, Postgrad Med J, 54 Suppl 1 (1978) 25-40.

[94] P. Malatesta, E. Hartfuss, M. Gotz, Isolation of radial glial cells by fluorescentactivated cell sorting reveals a neuronal lineage, Development (Cambridge, England), 127 (2000) 5253-5263.

[95] S.C. Noctor, A.C. Flint, T.A. Weissman, R.S. Dammerman, A.R. Kriegstein, Neurons derived from radial glial cells establish radial units in neocortex, Nature, 409 (2001) 714-720.

[96] L. Dimou, M. Gotz, Glial Cells as Progenitors and Stem Cells: New Roles in the Healthy and Diseased Brain, Physiological reviews, 94 (2014) 709-737.

[97] J. Morrens, W. Van Den Broeck, G. Kempermann, Glial cells in adult neurogenesis, Glia, 60 (2012) 159-174.

[98] H. Grandel, J. Kaslin, J. Ganz, I. Wenzel, M. Brand, Neural stem cells and neurogenesis in the adult zebrafish brain: origin, proliferation dynamics, migration and cell fate, Dev Biol, 295 (2006) 263-277.

[99] K. Ampatzis, P. Makantasi, C.R. Dermon, Cell proliferation pattern in adult zebrafish forebrain is sexually dimorphic, Neuroscience, 226 (2012) 367-381.

[100] M.R. Perez, E. Pellegrini, J. Cano-Nicolau, M.M. Gueguen, D. Menouer-Le Guillou, Y. Merot, C. Vaillant, G.M. Somoza, O. Kah, Relationships between radial glial progenitors 
and 5-HT neurons in the paraventricular organ of adult zebrafish - potential effects of serotonin on adult neurogenesis, Eur J Neurosci, 38 (2013) 3292-3301.

[101] I. Rothenaigner, M. Krecsmarik, J.A. Hayes, B. Bahn, A. Lepier, G. Fortin, M. Gotz, R. Jagasia, L. Bally-Cuif, Clonal analysis by distinct viral vectors identifies bona fide neural stem cells in the adult zebrafish telencephalon and characterizes their division properties and fate, Development (Cambridge, England), 138 (2011) 1459-1469.

[102] J.M. Bowers, J. Waddell, M.M. McCarthy, A developmental sex difference in hippocampal neurogenesis is mediated by endogenous oestradiol, Biol Sex Differ, 1 (2010) 8.

[103] L. Wang, S. Andersson, M. Warner, J.A. Gustafsson, Morphological abnormalities in the brains of estrogen receptor beta knockout mice, Proceedings of the National Academy of Sciences of the United States of America, 98 (2001) 2792-2796.

[104] R.A. Hill, H.K. Chua, M.E. Jones, E.R. Simpson, W.C. Boon, Estrogen deficiency results in apoptosis in the frontal cortex of adult female aromatase knockout mice, Mol Cell Neurosci, 41 (2009) 1-7.

[105] L. Wang, S. Andersson, M. Warner, J.A. Gustafsson, Estrogen receptor (ER)beta knockout mice reveal a role for ERbeta in migration of cortical neurons in the developing brain, Proceedings of the National Academy of Sciences of the United States of America, 100 (2003) 703-708.

[106] S. Suzuki, L.M. Gerhold, M. Bottner, S.W. Rau, C. Dela Cruz, E. Yang, H. Zhu, J. Yu, A.B. Cashion, M.S. Kindy, I. Merchenthaler, F.H. Gage, P.M. Wise, Estradiol enhances neurogenesis following ischemic stroke through estrogen receptors alpha and beta, The Journal of comparative neurology, 500 (2007) 1064-1075.

[107] L.Z. Li, Y.J. Bao, M. Zhao, 17beta-estradiol attenuates programmed cell death in cortical pericontusional zone following traumatic brain injury via upregulation of ERalpha and inhibition of caspase-3 activation, Neurochem Int, 58 (2011) 126-133.

[108] J.F. Soustiel, E. Palzur, O. Nevo, I. Thaler, E. Vlodavsky, Neuroprotective antiapoptosis effect of estrogens in traumatic brain injury, J Neurotrauma, 22 (2005) 345352.

[109] P.M. Wise, Estrogens and neuroprotection, Trends Endocrinol Metab, 13 (2002) 229-230.

[110] R.S. Peterson, C.J. Saldanha, B.A. Schlinger, Rapid upregulation of aromatase mRNA and protein following neural injury in the zebra finch (Taeniopygia guttata), Journal of neuroendocrinology, 13 (2001) 317-323.

[111] R.S. Peterson, D.W. Lee, G. Fernando, B.A. Schlinger, Radial glia express aromatase in the injured zebra finch brain, The Journal of comparative neurology, 475 (2004) 261269.

[112] C.J. Saldanha, K.A. Duncan, B.J. Walters, Neuroprotective actions of brain aromatase, Frontiers in neuroendocrinology, 30 (2009) 106-118.

[113] G.V. Callard, A.V. Tchoudakova, M. Kishida, E. Wood, Differential tissue distribution, developmental programming, estrogen regulation and promoter characteristics of cyp19 genes in teleost fish, The Journal of steroid biochemistry and molecular biology, 79 (2001) 305-314.

[114] P. Makantasi, C.R. Dermon, Estradiol treatment decreases cell proliferation in the neurogenic zones of adult female zebrafish (Danio rerio) brain, Neuroscience, (2014).

[115] N. Kishimoto, K. Shimizu, K. Sawamoto, Neuronal regeneration in a zebrafish model of adult brain injury, Dis Model Mech, 5 (2012) 200-209. 
[116] B. Ayari, K.H. El Hachimi, C. Yanicostas, A. Landoulsi, N. Soussi-Yanicostas, Prokineticin 2 expression is associated with neural repair of injured adult zebrafish telencephalon, J Neurotrauma, 27 (2010) 959-972.

[117] E.V. Baumgart, J.S. Barbosa, L. Bally-Cuif, M. Gotz, J. Ninkovic, Stab wound injury of the zebrafish telencephalon: a model for comparative analysis of reactive gliosis, Glia, 60 (2012) 343-357.

[118] P.L. Bardet, B. Horard, M. Robinson-Rechavi, V. Laudet, J.M. Vanacker, Characterization of oestrogen receptors in zebrafish (Danio rerio), J Mol Endocrinol, 28 (2002) 153-163.

[119] K. Mouriec, J.J. Lareyre, S.K. Tong, Y. Le Page, C. Vaillant, E. Pellegrini, F. Pakdel, B.C. Chung, O. Kah, I. Anglade, Early regulation of brain aromatase (cyp19a1b) by estrogen receptors during zebrafish development, Dev Dyn, 238 (2009) 2641-2651.

[120] G. Chandrasekar, A. Archer, J.A. Gustafsson, M. Andersson Lendahl, Levels of 17beta-estradiol receptors expressed in embryonic and adult zebrafish following in vivo treatment of natural or synthetic ligands, PloS one, 5 (2010) e9678.

[121] S. Pikulkaew, A. De Nadai, P. Belvedere, L. Colombo, L. Dalla Valle, Expression analysis of steroid hormone receptor mRNAs during zebrafish embryogenesis, General and comparative endocrinology, 165 (2010) 215-220.

[122] Y. Shi, X. Liu, P. Zhu, J. Li, K.W. Sham, S.H. Cheng, S. Li, Y. Zhang, C.H. Cheng, H. Lin, G-protein-coupled estrogen receptor 1 is involved in brain development during zebrafish (Danio rerio) embryogenesis, Biochem Biophys Res Commun, 435 (2013) 2127.

[123] L.B. Griffin, K.E. January, K.W. Ho, K.A. Cotter, G.V. Callard, Morpholino-mediated knockdown of ERalpha, ERbetaa, and ERbetab mRNAs in zebrafish (Danio rerio) embryos reveals differential regulation of estrogen-inducible genes, Endocrinology, 154 (2013) 4158-4169.

[124] F. Brion, Y. Le Page, B. Piccini, O. Cardoso, S.K. Tong, B.C. Chung, O. Kah, Screening estrogenic activities of chemicals or mixtures in vivo using transgenic (cyp19a1b-GFP) zebrafish embryos, PloS one, 7 (2012) e36069.

[125] M. Song, D. Liang, Y. Liang, M. Chen, F. Wang, H. Wang, G. Jiang, Assessing developmental toxicity and estrogenic activity of halogenated bisphenol A on zebrafish (Danio rerio), Chemosphere, 112 (2014) 275-281.

[126] S.H. Lam, M.M. Hlaing, X. Zhang, C. Yan, Z. Duan, L. Zhu, C.Y. Ung, S. Mathavan, C.N. Ong, Z. Gong, Toxicogenomic and phenotypic analyses of bisphenol-A early-life exposure toxicity in zebrafish, PloS one, 6 (2011) e28273.

[127] P. Coumailleau, E. Pellegrini, F. Adrio, N. Diotel, J. Cano-Nicolau, A. Nasri, C. Vaillant, 0. Kah, Aromatase, estrogen receptors and brain development in fish and amphibians, Biochimica et biophysica acta, (2014).

[128] X. Wang, Q. Dong, Y. Chen, H. Jiang, Q. Xiao, Y. Wang, W. Li, C. Bai, C. Huang, D. Yang, Bisphenol A affects axonal growth, musculature and motor behavior in developing zebrafish, Aquatic Toxicology, 142-143 (2013) 104-113.

[129] A. Riu, C.W. McCollum, C.L. Pinto, M. Grimaldi, A. Hillenweck, E. Perdu, D. Zalko, L. Bernard, V. Laudet, P. Balaguer, M. Bondesson, J.A. Gustafsson, Halogenated bisphenol-A analogs act as obesogens in zebrafish larvae (Danio rerio), Toxicological sciences : an official journal of the Society of Toxicology, 139 (2014) 48-58.

[130] K. Petersen, E. Fetter, O. Kah, F. Brion, S. Scholz, K.E. Tollefsen, Transgenic (cyp19a1b-GFP) zebrafish embryos as a tool for assessing combined effects of oestrogenic chemicals, Aquatic toxicology (Amsterdam, Netherlands), 138-139 (2013) 88-97. 
[131] J. Wang, X. Shi, Y. Du, B. Zhou, Effects of xenoestrogens on the expression of vitellogenin (vtg) and cytochrome P450 aromatase (cyp19a and b) genes in zebrafish (Danio rerio) larvae, Journal of environmental science and health. Part A, Toxic/hazardous substances \& environmental engineering, 46 (2011) 960-967.

[132] W.K. Tse, B.H. Yeung, H.T. Wan, C.K. Wong, Early embryogenesis in zebrafish is affected by bisphenol A exposure, Biology open, 2 (2013) 466-471.

[133] C.D. Kinch, K. Ibhazehiebo, J.H. Jeong, H.R. Habibi, D.M. Kurrasch, Low-dose exposure to bisphenol A and replacement bisphenol S induces precocious hypothalamic neurogenesis in embryonic zebrafish, Proceedings of the National Academy of Sciences of the United States of America, 112 (2015) 1475-1480.

[134] M. Vosges, Y. Le Page, B.C. Chung, Y. Combarnous, J.M. Porcher, O. Kah, F. Brion, 17alpha-ethinylestradiol disrupts the ontogeny of the forebrain GnRH system and the expression of brain aromatase during early development of zebrafish, Aquatic toxicology (Amsterdam, Netherlands), 99 (2010) 479-491.

[135] M. Vosges, O. Kah, N. Hinfray, E. Chadili, Y. Le Page, Y. Combarnous, J.M. Porcher, F. Brion, 17alpha-Ethinylestradiol and nonylphenol affect the development of forebrain GnRH neurons through an estrogen receptors-dependent pathway, Reprod Toxicol, 33 (2012) 198-204. 